\title{
Non-uniform dispersion of toughening agents and its influence on the mechanical properties of polypropylene
}

\author{
Z. Li, C. M. Liu, H. L. Liu, K. Wang, Q. Fu* \\ College of Polymer Science and Engineering, State Key Laboratory of Polymer materials Engineering, Sichuan \\ University, 610065 Chengdu, China
}

Received 30 September 2013; accepted in revised form 25 November 2013

\begin{abstract}
To achieve excellent properties of polymer blends and composites, good dispersion and uniform distribution of second component or filler in the matrix are often required. However, more and more evidences reveal that uniform distribution is not always the best. To further prove this idea, in this work, we purposely designed and prepared different samples of isotactic polypropylene (iPP)/elastomer or iPP/ $\beta$-nucleating agent with uniform and non-uniform distribution of the modifiers via stacking the blending sheets in different sequence. It was found that for a given amount of toughening agent, the impact strength of polymer blends with non-uniform distribution of elastomer or $\beta$-nucleating agent could be much higher than its uniformly dispersed counterpart, while the tensile strength and tensile modulus remain relatively constant. The instrumented impact test confirmed that among the samples with different layered structures, the absorbed energy during crack initiation differs little from each other. Whereas absorbed energy during crack propagation process shows the same trend as final impact strength, making it the controlling parameter during the impact process. When cracks are initiated at higher toughening agents content side, the relatively smooth fracture surfaces near the crack edge area proved that they absorb small energy and the adjacent inner part showed obviously plastic deformation, corresponding to higher energy absorption. Our work demonstrates again that design and control of the hierarchical structure of polymer articles is vital for high performance properties and non-uniform distribution of filler could be much better than the uniform distribution.
\end{abstract}

Keywords: mechanical properties, poly(ethylene-1-octene), nucleating agents, heterogeneous distribution

\section{Introduction}

In the last decades, the development of polymeric matrix composites mainly focused on uniformly dispersed polymeric composites (UDPCs). The conventional view believes that the uniform distribution of the second component like nano-particles, elastomers, fibers and so forth contributes to the better properties of the composites. Undeniably, scientific researchers have achieved high performance of polymeric composites by this guiding ideology. However, as the rapid development of science and technology, the material application places higher demands on polymeric composites and the homogeneously distributed components not always yield the most satisfactory effect [1-3]. Besides, their engineering and structural applications are restricted due to high production cost of nanoscale reinforcing materials. Heterogeneous spatial distribution of two or more components along the thickness of the product may have better performance characteristics such as thermal stress relaxation, adhesive property and mechanical properties as compared to the same material in homogeneous compositional state and this gives scientists a wide range of possibilities to manipulate the properties of these materials depending on requirements and future applications [4]. For example, Bafekrpour et al. [5] realized a heterogeneous distribution of graphite in phenolic matrix

\footnotetext{
${ }^{*}$ Corresponding author, e-mail: qiangfu@scu.edu.cn

(C) BME-PT
} 
using powder stacking and compression molding techniques. The authors reported that the nanocomposites with the highest graphite content layer on the top and bottom surfaces and the lowest in the center, showed the highest improvement of thermomechanical properties and creep recovery among all filler distribution conditions. Lee and Jang [6] found that, if the face of a sample with high glass fiber content was loaded, the flexural strength and the impact energy of the composite showed improved values by comparison with those of the isotropic composite. Wang et al. [7] prepared a gradient polymer with a progressive change in sulfur content along the thickness direction and the composites showed a broad damping temperature range spanning over $100^{\circ} \mathrm{C}$, which is far better than the isotropic ones with the same sulfur density.

Based on the above, we are wondering if the concept of non-uniform dispersion can be used in the isotactic polypropylene (iPP) toughening area to further enhance its impact strength. It has been long known that PP is a semi-crystalline polymer and has been widely used. But its toughness, and in particular its notched toughness, is insufficient for PP to be used as an engineering plastic. To solve the problem, elastomers like poly (ethylene-1-octene) (POE) and $\beta$-nucleating agents (NA) are the two broad types of modifiers to achieve the high impact resistance of PP [8-20]. PP is toughened by POE and NA through totally different mechanism: the former relies on the energy absorption of elastomer particles when impacting whereas NA can promote the growth of $\beta$-crystals instead of the $\alpha$-form and $\beta$-nucleated PP shows better impact resistance [21-25]. Generally the incorporation of the modifiers always causes decrease in the tensile properties. So the POE and NA are always kept below a certain limit [26-27].

In this study, we demonstrate for the first time the design and fabrication of non-uniformly dispersed polymeric composites (N-UDPCs) of PP/POE and PP/NA system by sheet stacking and compression molding. Four N-UDPCs and UDPCs with the same thickness and total modifier contents were fabricated to evaluate the effect of spatial distribution of toughening agents on the mechanical properties.
The impacting process and fracture morphology were also investigated and characterized.

\section{Experimental}

\subsection{Materials}

iPP T30S (Dushanzi, China) with density $(\rho)=$ $0.91 \mathrm{~g} / \mathrm{cm}^{3}$, was the commercial product of Dushanzi Co. Ltd, China. The weight-average molecular weight $\left(M_{\mathrm{w}}\right)$ of the iPP was $3.9 \cdot 10^{5} \mathrm{~g} / \mathrm{mol}$ and the molecular weight distribution (MWD) was 4.6. POE 8150 with $\rho=0.868 \mathrm{~g} / \mathrm{cm}^{3}$ was supplied by Du Pont Dow Elastomers Co. Ltd., USA. The octene content was $25 \mathrm{wt} \%$. The rare earth $\beta$-nucleating agent was kindly supplied by Winner Functional Materials Co. (Foshan, Guangdong, China). Its composition is hetero-nuclear dimetal complexes of lanthanum and calcium containing some specific ligands [28].

\subsection{Sample fabrication}

PP samples with varied POE contents were melt compounded in a co-rotating twin screw extruder (TSSJ-25 co-rotating twin-screw extruder, China) with the setting temperatures of $160-200^{\circ} \mathrm{C}$ from hopper to die and the screw speed of $120 \mathrm{rpm}$. After making droplets, the pellets were dried at $80^{\circ} \mathrm{C}$ for $12 \mathrm{~h}$. The composite sheets were moulded by hot pressing at $200^{\circ} \mathrm{C}$. The $\mathrm{POE}$ content in the various composites was 0,10 , and $20 \%$ by weight. The thickness of each composite sheet was about $1.8 \mathrm{~mm}$.

To obtain the non-uniformly dispersed polymeric composites (N-UDPCs) of PP/POE, composites with varying POE content through the thickness of the specimen were manufactured. Four sheets were stacked and heated to $200^{\circ} \mathrm{C}$ and compression moulded. The moulding pressure was $0.6 \mathrm{MPa}$ and this pressure was maintained during cooling $\left(-5^{\circ} \mathrm{C} / \mathrm{min}\right)$ to room temperature, guaranteeing the thickness of all the samples being ca $7 \mathrm{~mm}$. A range of compositions with different stacking sequence were made as illustrated in Figure 1. All the samples are prepared with four layers with same POE content of $10 \mathrm{wt} \%$. POE10 is uniformly dispersed polymeric composites (UDPCs) with the average mass fraction of POE in PP (i.e. $10 \mathrm{wt} \%$ ). $2 \mathrm{PP} /$
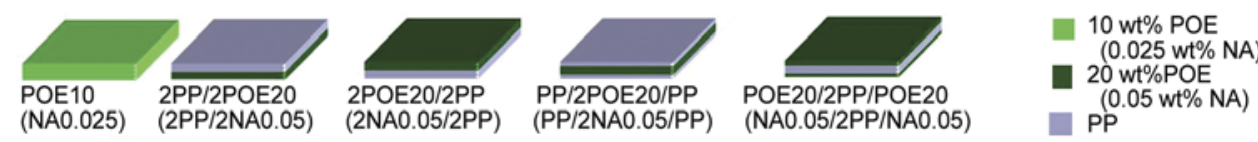

Figure 1. Illustrations of different layered structure of PP/POE and PP/NA composites 
2POE20 has two layers of neat PP on the top and $20 \mathrm{wt} \%$ of POE in the bottom two layers. 2POE20/ $2 \mathrm{PP}$ has a reverse compositional change in comparison to $2 \mathrm{PP} / 2 \mathrm{POE} 20$. $\mathrm{PP} / 2 \mathrm{POE} 20 / \mathrm{PP}$ has two layers of $20 \mathrm{wt} \%$ POE in the core and neat PP layer on the top and bottom. In contrast, POE20/2PP/POE20 has neat $\mathrm{pp}$ in the core and $20 \mathrm{wt} \%$ POE on the side.

Similarly, N-UDPCs and UDPCs of PP/NA with $0.05 \mathrm{wt} \%$ NA were fabricated according to the same procedure. It shares the same illustration as $\mathrm{PP} / \mathrm{POE}$ composites does in Figure 1.

To make sure that the individual layers could be well fused and avoid interlayer defects, two measures were taken. The first is that control the moulding pressure at $0.6 \mathrm{MPa}$ during the cooling process. Another is that the inner air pressure was kept at $-0.1 \mathrm{MPa}$ to avoid the bubbles between different layers.

\subsection{Characterizations and measurements Mechanical tests}

A SANS universal testing machine (Shenzhen, China) was used to measure the tensile properties, with a tensile rate of $50 \mathrm{~mm} \cdot \mathrm{min}^{-1}$. Tensile measurements were made on rectangular specimens ca $7 \mathrm{~mm}$ wide (the thickness of the laminated molded samples), $2 \mathrm{~mm}$ thick and with gauge length of $60 \mathrm{~mm}$. A crosshead speed of $50 \mathrm{~mm} / \mathrm{min}$ was applied to determine the tensile strength, elongation at break and tensile modulus.

Conventional Izod tests can provide information on the impact resistance of materials during high strain rate deformation; no other valuable data can be obtained except the final impact strength, especially in the inhomogeneous filler distribution system [29, 30]. Therefore, in this experiment, instrumented falling weight impact test (IFWIT) was used to detect the impact force changing trend versus displacement, establishing the correlation between filler distribution and impact strength

IFWIT was performed on a TCJ-25 (Jilin Taihe Tester Co. Ltd, China) machine. $80 \times 7 \times 4 \mathrm{~mm}$ specimens were cut from the laminated molded samples as illustrated in Figure 2a, taken POE20/2PP/POE20 for instance. The specimens were notched on the top side according to Figure 1 with $0.3 \mathrm{~mm}$ notch depth. To be clarified, 2POE20/2PP iPP means the PP Side was notched whereas 2POE20/2PP iPOE means POE20 has the breach. Impact testing was carried out at $3.5 / \mathrm{s}$ velocity and $7.5 \mathrm{~J}$ maximal energy. The samples were tested at room temperature $\left(24^{\circ} \mathrm{C}\right)$.

Figure $2 \mathrm{~b}$ also shows a typical force-deflection curve derived from an impact test on a PP/POE composite. In a typical force-displacement curve, the peak force $\left(F_{\mathrm{m}}\right)$ is the maximum force that the specimen can sustain on fracture, indicating the beginning of significant damage. The associated energy absorbed up to this point is symbolized by $E_{\mathrm{i}}$. It is calculated by integrating the area under the loaddisplacement curve and represents the energy to initiate crack. After $F_{\mathrm{m}}$, the dropping off in force indicates crack propagation. $E_{\mathrm{p}}$ represents the energy absorption in this phase. The total energy absorption $E_{\mathrm{t}}$ is $E_{\mathrm{t}}=E_{\mathrm{i}}+E_{\mathrm{p}}$.

This is the area under the entire force-deflection curve $[31,32]$.

\section{Scanning electron microscope (SEM)}

The scanning electron microscopy (SEM) experiments were performed using an FEI Inspect F SEM instrument with an acceleration voltage of $20 \mathrm{kV}$. For morphological observations the PP/POE samples were firstly cryo-fractured in liquid nitrogen and then etched chemically in xylene at $60^{\circ} \mathrm{C}$ for $40 \mathrm{~min}$, followed by washing and drying. Impact fractured surface of both the PP/POE and PP/NA specimens were also investigated. All samples were sputter-coated with gold powder before test.

\section{Differential scanning calorimetry (DSC)}

The thermal analysis of the samples was conducted using a Perkin-Elmer pyris-1 DSC with nitrogen as the purge gas, calibrated by indium. The mass of tested sample was about $5 \mathrm{mg}$. In order to prove the anistropic structure, the samples cut from the different layers of PP/NA specimens were directly heated from 30 to $200^{\circ} \mathrm{C}$ with a rate of $10^{\circ} \mathrm{C} / \mathrm{min}$ and held for $5 \mathrm{~min}$ to eliminate any thermal history, and then cooled to $50^{\circ} \mathrm{C}$ at the rate of $10^{\circ} \mathrm{C} / \mathrm{min}$. Thereafter, the specimens were heated a gain to the melting point at a rate of $10^{\circ} \mathrm{C} / \mathrm{min}$. The relative content of $\beta$-form estimated by DSC melting curve is defined as $K_{\beta}{ }^{*}$ and calculated from the Equation (1):

$K_{\beta}^{*}=\frac{X_{\beta}}{X_{\alpha}+X_{\beta}}$

where $X_{\alpha}$ and $X_{\beta}$ are the relative crystallinity of the $\alpha$ - and $\beta$-form, respectively and could be calculated separately according to Equation (2): 


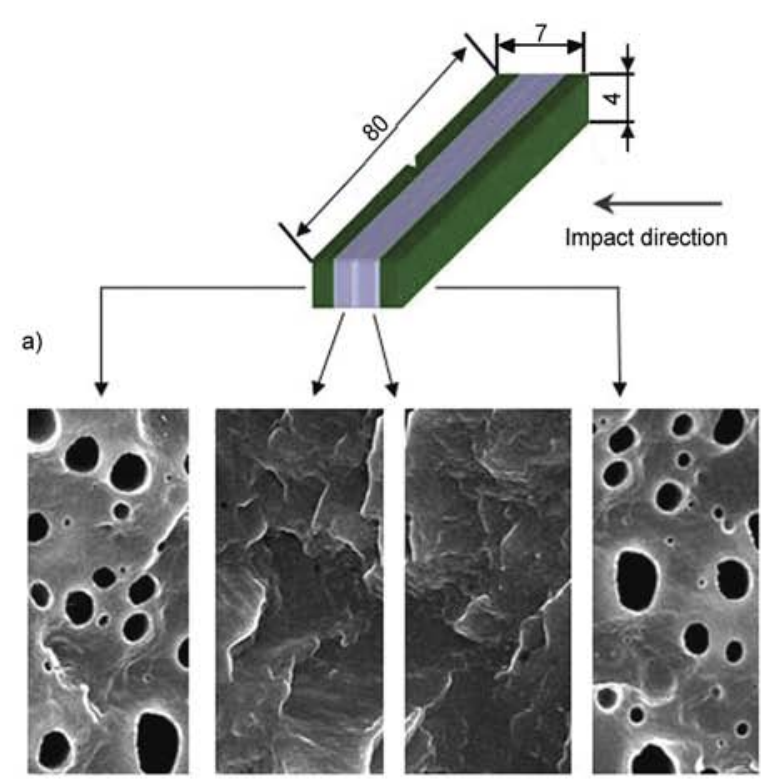

c)

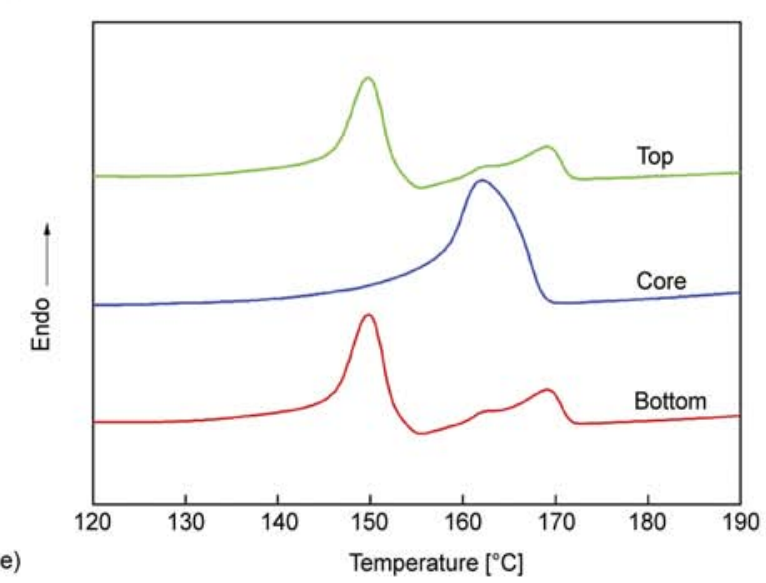

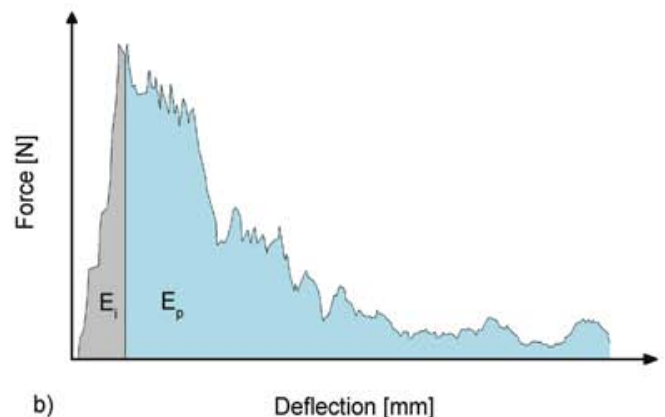

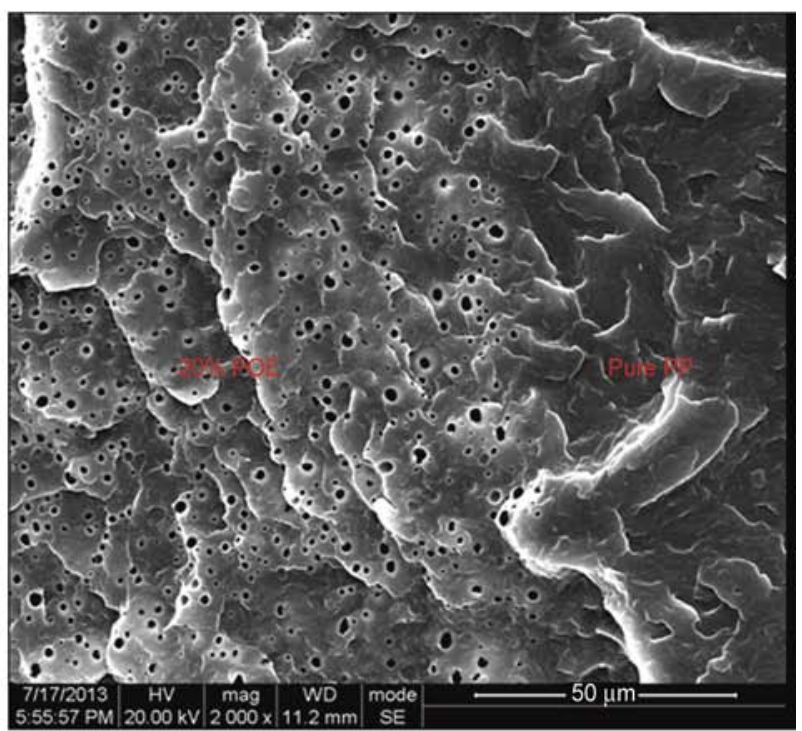

d)

Figure 2. (a) The sketch of layered structure of POE20/2PP/POE20, (b) schematic diagram of Charpy impact measurement and schematic diagram of $E_{\mathrm{i}}$ and $E_{\mathrm{p}}$ of a force-deflection curve, (c) structure morphology across the thickness of the specimen of POE20/2PP/POE20, (d) the interfaces of POE20/2PP/POE20, (e) DSC heating curves of the samples cut from different part of NA0.05/2PP/NA0.05 specimen

$X_{\mathrm{i}}=\frac{\Delta H_{\mathrm{i}}}{\Delta H_{\mathrm{i}}^{0}}$

where $\Delta H_{\mathrm{i}}$ is the calibrated specific fusion heat of either $\alpha$-form or $\beta$-form, and $\Delta H_{\mathrm{i}}^{0}$ is the standard fusion heat of either $\alpha$ - or $\beta$-form, which is $177 \mathrm{~J} / \mathrm{g}$ for the $\alpha$ form and $168.5 \mathrm{~J} / \mathrm{g}$ for the $\beta$-form [33].

\section{Results and discussion}

\subsection{Specimen structure}

The sandwich structure of PP/POE system was detected by SEM. Figure $2 \mathrm{c}$ shows different structure morphology across the thickness of the specimen and Figure 2d illustrates the interface of POE20/ 2PP/POE20. The layers were homogeneous and had clear interlayer boundaries. Despite high concentrations of POE, no interlayer defects, delamination or cracking was observed. It proved that the vacuum compression molding successfully drive the bubbles away during melting and cooling process. From the etched SEM figure, it is also clear that the POE domains were well dispersed in the PP matrix. Because NA0.05 merged well with PP, the layered structure is hardly seen from SEM. DSC was used to discriminate the different layers. As the samples taken from NA0.05/PP/NA0.05, The DSC melting thermograms of the three samples from different positions are shown in Figure 2e. For the top and bottom layers, the melting traces exhibit the same three endothermic melting peaks. The endothermic 
peak at low temperature should be associated with the melting of the $\beta$-form. The middle endothermic peak approximately located at $165^{\circ} \mathrm{C}$ is characteristic for the melting of the original $\alpha$-form. While the last endothermic peak approximately located at $169^{\circ} \mathrm{C}$ is characteristic for the melting of more perfect $\alpha$-form deriving from $\beta$-to- $\alpha$ re-crystallization [22-24, 34, 35]. Quantitative estimations of relative fraction of $\beta$-form $\left(K_{\beta}{ }^{*}\right)$ been done according to the methods mentioned in the experimental section, and the values of the samples from top layers, core area and bottom layers are $68.2,0$ and $70.4 \%$ respectively. In addition, the amount of $\beta$-phase in sample NA0.025 is $12.3 \%$.

Combined with the results of SEM and DSC, it can be concluded that the layered structures were well preserved during the compression molding process.

\subsection{Tensile properties}

Table 1 illustrates the tensile properties of PP/POE and PP/NA composites respectively. It shows the tensile properties of N-UDPCs differ little from UDPCs. Generally, the incorporation of POE and $\beta$ nucleating agent always leads to the decrease of tensile properties and the more content of fillers, the poorer tensile performance. Unexpectedly, in the $\mathrm{PP} /$ POE and PP/NA systems, the either tensile strength or tensile modulus just shows slight decline. The tensile strength and modulus of PP is higher than any components filled with POE or NA. Therefore when the tension is imposed on the anisotropic specimens, the neat PP layer acts as the main load-bearing skeleton and it compensates the strength loss brought by layers with $20 \mathrm{wt} \%$ POE or $0.05 \mathrm{wt} \%$ NA. That may explain the tensile properties do not fluctuate too much whether or not the filler is uniformly dispersed in PP matrix.

\subsection{Impact strength}

The final instrumented impact strength of $\mathrm{PP} / \mathrm{POE}$ composites is illustrated in Figure 3a. It can be easily seen that with different POE spatial distribution through the thickness, the composites respond totally different to the impact force. POE20/2PP/POE20 and 2POE20/2PP iPOE get the highest impact strength among the all. However, when POE was uniformly dispersed in PP matrix with the content of $10 \mathrm{wt} \%$, the value of impact strength is only half of that compared to the former two composites. With the same average POE content, when the breaches was notched on the PP side, the impact strength value of $\mathrm{PP} /$ 2POE20/PP and 2POE20/2PP iPP are lower than POE10. In this circumstance, POE domains in the matrix fail to resist impact forces. By comparison, we can see that although 2POE20/2PP iPOE and 2POE20/2PP iPP have the same layered structure

Table 1. the tensile properties of the two series of composites PP/POE series and PP/NA series

\begin{tabular}{|l|c|c|l|c|c|}
\hline & $\begin{array}{c}\text { Tensile strength } \\
{[\mathbf{M P a}]}\end{array}$ & $\begin{array}{c}\text { Tensile modulus } \\
{[\mathbf{M P a}]}\end{array}$ & & $\begin{array}{c}\text { Tensile strength } \\
{[\mathbf{M P a}]}\end{array}$ & $\begin{array}{c}\text { Tensile modulus } \\
{[\mathbf{M P a}]}\end{array}$ \\
\hline POE20/2PP/POE20 & $31.7 \pm 0.6$ & $1025.7 \pm 120.6$ & NA0.05/2PP/NA0.05 & $30.6 \pm 1.5$ & $894.3 \pm 75.0$ \\
\hline 2POE20/2PP & $30.3 \pm 0.6$ & $1048.8 \pm 50.2$ & $2 \mathrm{NA} 0.05 / 2 \mathrm{PP}$ & $30.8 \pm 1.8$ & $861.1 \pm 81.5$ \\
\hline POE10 & $31.0 \pm 0.5$ & $1112.5 \pm 60.4$ & NA0.025 & $33.1 \pm 0.9$ & $829.2 \pm 52.3$ \\
\hline PP/2POE20/PP & $32.7 \pm 0.5$ & $1091.0 \pm 148.8$ & PP/2NA0.05/PP & $31.4 \pm 1.6$ & $884.8 \pm 167.9$ \\
\hline
\end{tabular}
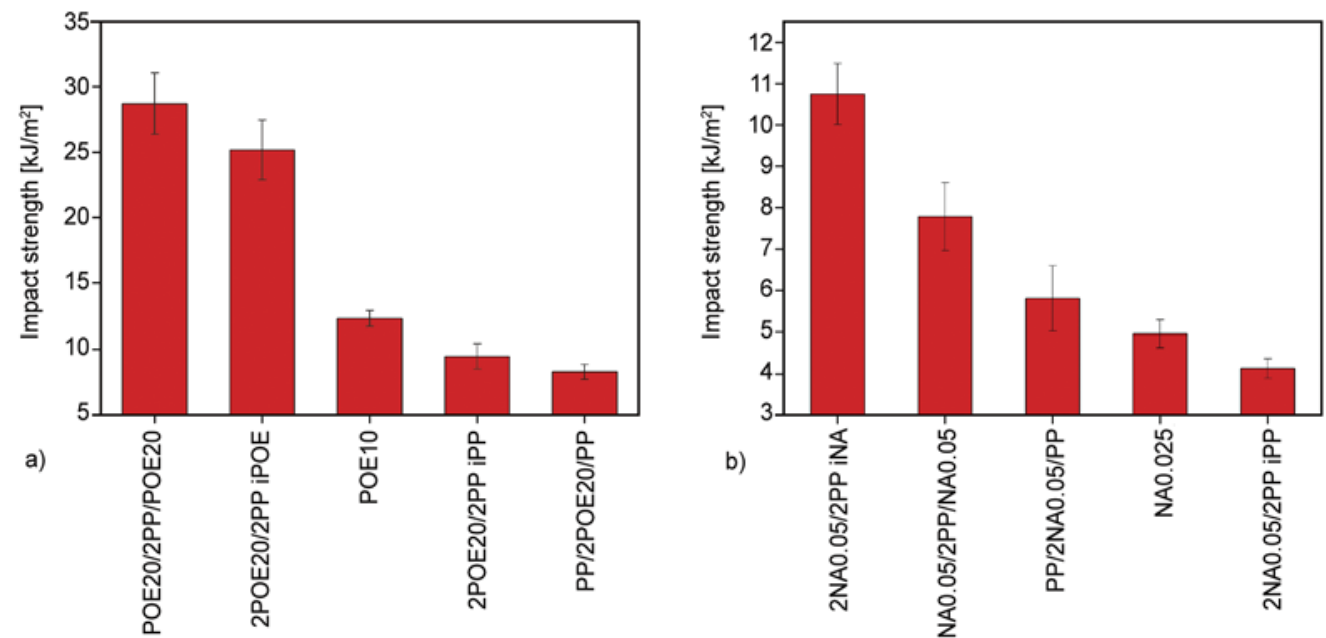

Figure 3. Impact strength of (a) PP/POE composites and (b) PP/NA composites 

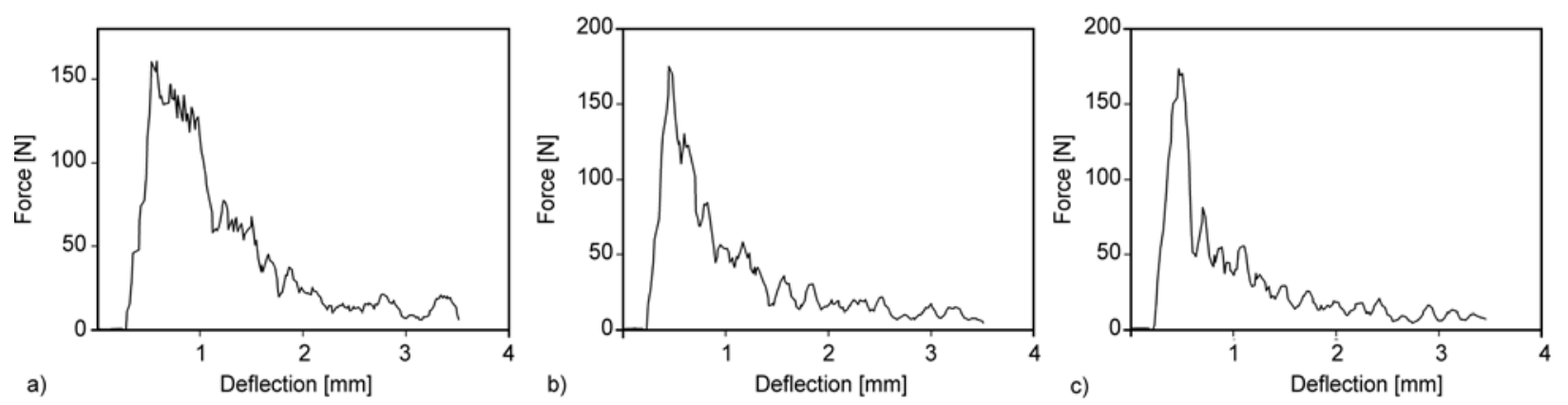

Figure 4. Force-displacement curves of (a) 2POE20/2PP, (b) POE10 and (c) PP/2POE20/PP
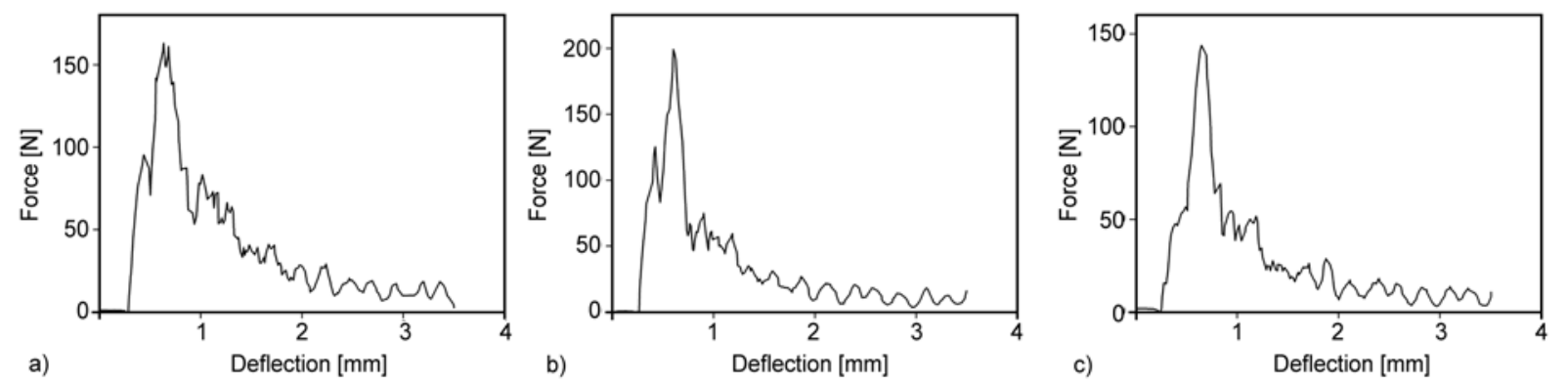

Figure 5. Force-displacement curves of (a) 2NA0.05/2PP iNA, (b) NA0.025 and (c) 2NA0.05/2PP iPP

and POE content, the impact strength is quite different due to the opposite bleach position.

Apart from the final impact strength as illustrated above, the force-displacement curve was also obtained as shown in Figure $4 \mathrm{a}, 4 \mathrm{~b}$ and $4 \mathrm{c}$, corresponding to 2POE20/2PP iPOE, POE10 and PP/2POE20/ $\mathrm{PP}$ respectively. The traces of the three specimens show almost the same linear increase in force to the peak force $\left(F_{\mathrm{m}}\right)$ where the damage is initiated. Deformation and fracture of the matrix takes place in an area in front of the notched crack tip. It is obvious that even though the three composites have the same POE content, the force-displacement curves are totally different from each other after damage initiation. There is a sharp dropping off in force of POE10 and PP/2POE20/PP. That implies that less energy was absorbed in the damage propagation process compared with 2POE20/2PP iPOE, showing a dropping off in several stages after the specimen reaches $F_{\mathrm{m}}$. Hence, the gradual dropping off leads to more energy absorption associated with higher impact strength.

Figure 6a compares $E_{\mathrm{t}}, E_{\mathrm{i}}$ and $E_{\mathrm{p}}$ of all the five series of specimens, giving a quantitative explanation for the impacting process. As is predicated, the value of $E_{\mathrm{t}}$ has the same changing trend as that of the impact strength for different layer arrangement. However, the values of $E_{\mathrm{i}}$ don't show apparent differences among the specimens. This indicates again that the different POE distribution doesn't significantly influence the energy absorption before the peak force is reached. It should be noted that the values of $E_{\mathrm{p}}$ are strongly influenced by the different layered structure and have the same changing trend as the impact strength does. Clearly, it is the $E_{\mathrm{p}}$ that finally affects the impact strength. For POE20/2PP/ POE20 and 2POE20/2PP iPOE, the values of $E_{\mathrm{p}}$ are maintained at a higher level, whereas for POE10, 2POE20/2PP iPP and PP/2POE20/PP, the values of $E_{\mathrm{p}}$ shows dramatic dropping off. To explain the results, the different layered structure should be well considered. From the force-displacement curves, the damage initiates at a relatively short time and the forces have reached its maximum with the replacement being less than $0.1 \mathrm{~mm}$. In other words, when the damage initiation ends, the crack depth is at most $0.4 \mathrm{~mm}$ plus the notched depth. For POE20/ 2PP/POE20 and 2POE20/2PP iPOE respectively have one layer with $1.8 \mathrm{~mm}$ thick and two layers with $3.6 \mathrm{~mm}$ thick of $20 \mathrm{wt} \%$ POE on the top. Therefore, when the damage propagation begins, the crack tip still remains in the POE20 layer which absorbs the most energy in the impact process. The specimens absorb most of the energy before $1.5 \mathrm{~mm}$. It means that by purposely arranging POE layers on the notched top, they can effectively absorb the energy $\left(E_{\mathrm{i}}+E_{\mathrm{p}}\right)$ during the impacting process. For POE10, 2POE20/2PP iPP and PP/2POE20/PP, the damage 

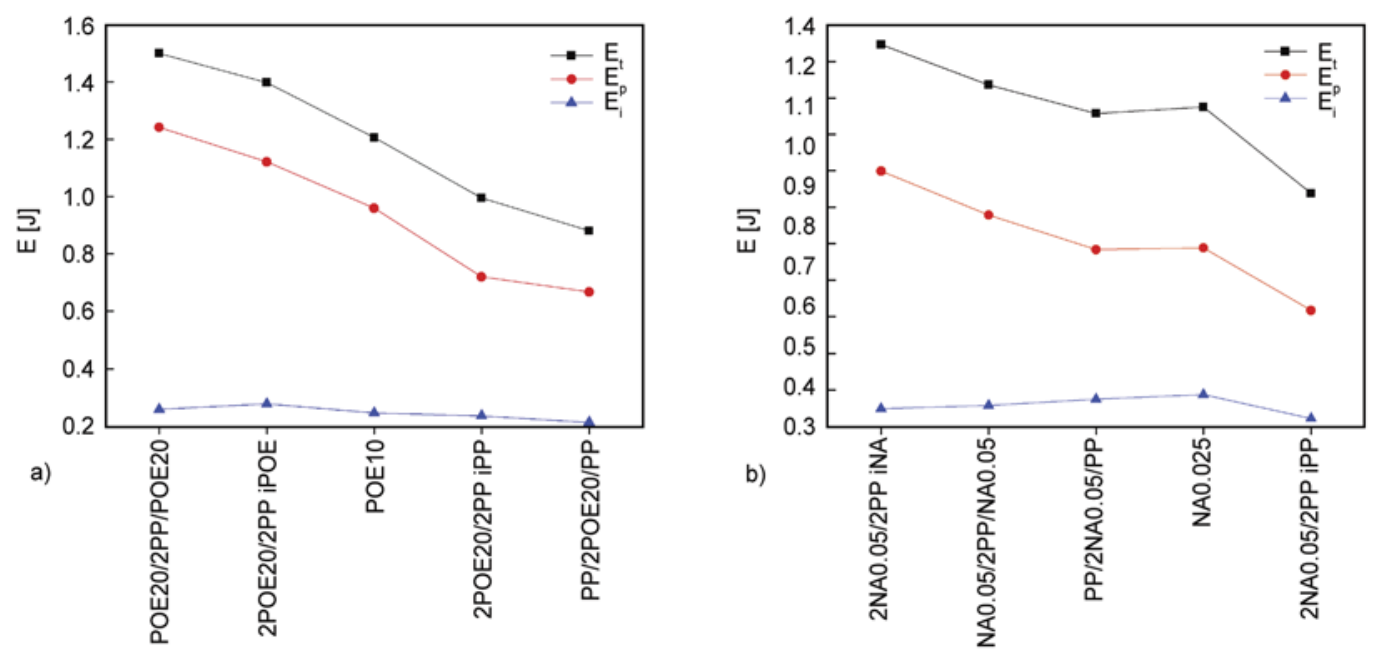

Figure 6. Illustration of $E_{\mathrm{t}}, E_{\mathrm{p}}, E_{\mathrm{i}}$ of (a) PP/POE composites and (b) PP/NA system

propagated in POE10 and PP layers and they show poor ability to hinder crack from propagating. According to the theory, 2POE20/PP iPOE seems to have higher impact strength than POE20/2PP/POE20, but the result is opposite. To make this clear, It is suggested that the reinforcing POE20 blend absorbs much energy by activation of multiple crazing events at a stress level below that of the crack initiation in the inner PP layer. Thereby, cracks in the PP layer can only occur when a very high degree of damage as already occurred in the outer POE20 layer. Even when cracks start to be initiated and propagate in the PP layer, the POE20 layer on the opposite side of the impact works to arrest crack propagation to rupture till too much cracks have propagated through the PP layer. It is perfectly consistent with the fact that the POE20/PP iPOE structure has lower impact resistance than the POE20/2PP/POE20 sandwich structure when impacted on the POE20 side, since no toughened layer can stop the cracks at the exit of the PP layer

The above results prove to us that the hierarchical structure of the specimens has displayed its superiority over POE uniformly dispersed ones. To verify the universality of the theory, the series of PP/NA specimens were also prepared since $\beta$-nucleating agents have the totally different toughening mechanism from elastomers. The impact process was investigated according to the same procedure.

Similarly, in the PP/NA system, different layer arrangement contributes to the variation on impact strength, seen from Figure 3b. 2NA0.05/2PP iNA shows the highest resistance to impact force, followed by NA0.05/2PP/NA0.05. Both of the two performed better than that NA was evenly dispersed in the PP matrix at $0.025 \mathrm{wt} \%$. It should be pointed out that the amount of $\beta$-phase PP in NA0.05 layer is far more than that in NA0.025 and the result seems reasonable since the amount of $\beta$-phase has the critical influence on impact strength. Like 2POE20/2PP iPP and $\mathrm{PP} / 2 \mathrm{POE} 20 / \mathrm{PP}$, when the PP sides were notched, NA0.05/PP iPP and PP/NA0.05/PP show poor impact resistance. It seems like neither POE nor $\beta$ nucleated PP worked effectively in the four components of which cracks initiate from the PP sides.

Figure $5 \mathrm{a}, 5 \mathrm{~b}$ and $5 \mathrm{c}$ illustrate the force-displacement curves of 2NA0.05/2PP iNA, NA0.025 and 2NA0.05/2PP iPP. Like the curves obtained from the PP/POE composites, the force changing trends versus displacement are nearly the same before. 2NA0.05/2PP iNA obviously decrease the slope of the force reduction after $F_{\mathrm{m}}$ so that a larger deflection and hence higher $E_{\mathrm{p}}$ can be achieved. Because PP do not show obvious toughness enhancement when the NA content is controlled at $0.025 \mathrm{wt} \%$, the traces of NA0.025 and 2NA0.05/2PP iPP have the same patterns. The reason is understandable since the amount of $\beta$-nucleated PP in NA0.05 is far more than that in NA0.025 and the $\beta$-phase can absorb most of energy during the crack propagation process. The content of $\beta$-phase PP in NA0.025 is too low to be impact resistant.

$E_{\mathrm{t}}, E_{\mathrm{i}}$ and $E_{\mathrm{p}}$ of all the five PP/NA specimens are also obtained from respective force-deflection curve as illustrated in Figure 6b. Et has the same trend as the finally impact strength does. The essential factor controlling the impact performance is still the energy during crack propagation $\left(E_{\mathrm{t}}\right)$.

However in PP/NA composites, the impact strength sequence is not in accord with that of PP/POE com- 
posites. For example, 2NA0.05/2PP iNA shows the best ability to resist impact force, whereas for $\mathrm{POE}$ reinforced PP matrix, POE20/2PP/POE20 has the highest impact strength. That may have something to do with the totally different toughening mechanism of NA and POE. PP is toughened by POE through the energy absorption of elastomer particles when impacting and the crystal form of PP change little, whereas NA can promote $\beta$-crystals instead of $\alpha$-form and $\beta$-nucleated PP shows better impact resistance. The major difference is the significantly lower impact strength due to the lower energy-dissipating property of $\beta$-nucleated PP as compared to the POE/PP blends. Nevertheless, it has to be admitted that when the sides have high content of POE and $\beta$-nucleated PP where the cracks initiate, the corresponding specimens: POE20/2PP/ POE20, 2POE20/2PP iPOE, NA0.05/2PP/NA0.05 and 2NA0.05/2PP iNA show higher impact strength than the specimens when the corresponding toughening agents are uniformly dispersed in PP matrix. That successfully proves that uniformly distribution of the modifiers is not always the best solution to toughen the matrix.

\subsection{Fracture morphology}

The impact process of composite materials is so complicated that it is unrealistic to completely figure out the toughening mechanism just through IFWIT. To help better understand the impact process, the fractured surfaces of the specimens were investigated by SEM. Figure $7 a_{1}$ shows part of the fractured surfaces of 2POE20/2PP iPOE where the cracks initiate from the $20 \mathrm{wt} \%$ POE layer. By careful observation, the fractured $20 \mathrm{wt} \%$ POE layer appears two different regions. Figure $7 a_{3}$ is near the notched tip and Figure $7 a_{2}$ is somewhat far from the notched side. Combined with the force-displacement curve, the two areas are corresponded with the damage initiation and propagation stage, respectively. At higher magnification, one can observe that in the crack initiation region Figure $7 a_{3}$, most of the POE particles are still embedded in PP matrix. As discussed above, the initiating process happens at so short a time that POE particles fail to respond to the impact force. That explains why $E_{\mathrm{i}}$ didn't show obvious enhancement when the force reached the maximum. Contrast with the edge region, the inner area of POE20 layer shows a typical sea-island structure of elastomer enhancement system. The pulling out of POE particles from PP matrix absorbs most of the energy during damage propagation process. The fractured surface pictures agree well with the result obtained from instrumented impact test.

The fracture surface of 2NA0.05/2PP iNA is illustrated in Figure $7 b_{1}$. The interfaces of different layers are blurred and the fracture surfaces of the damage initiation and propagation process do not differ too much. However, at higher magnification the difference can still be found even it is not so obvious. The edge area Figure $7 b_{3}$ exhibits the typical surface of brittle fracture mode. The plastic deformation zone is relative small and smooth, implying little impact energy is absorbed in that area. The inner region Figure $7 b_{2}$ corresponding to damage propagation process fracture surface shows a little more obvious plastic deformation and the extent of plastic deformation increases somewhat.

The evolution of fracture morphology from external crack tip to internal crack propagation area agrees well with the IFWIT result. It explains why the specific N-UDPCs (e.g. POE20/2PP/POE20) perform better than UDPCs (e.g. POE10) from another perspective.

\section{Conclusions}

In this study, PP based N-UDPCs were prepared by sheets stacking and compression moulding method. The layered structures of PP/POE and PP/NA composites were confirmed by SEM and DSC results respectively. The effect of spatially heterogeneous POE and NA content on the impact and tensile properties has been investigated. Regardless of the layer arrangement, tensile strength of anisotropic composites do not decline compared with the filler uniformly distributed ones. Although having the same filler content, composites with different modifiers distribution showed peculiar impact properties. When the crack initiate from the high filler content side, like 2POE20/2PP iPP, POE20/2PP/POE20, $2 \mathrm{NA} 0.05 / 2 \mathrm{PP}$ iNA and NA0.05/2PP/NA0.05, the impact strength is obviously higher than that of the filler uniformly distributed ones. Regardless of the different toughening mechanisms of POE and $\beta$ nucleating agent, the instrumented impact test has the similar result. The essential factor controlling the final strength is the absorbed energy during damage propagation process. In addition the morphology result confirms the results from another point of view. In a word, the enhancement of impact strength was 


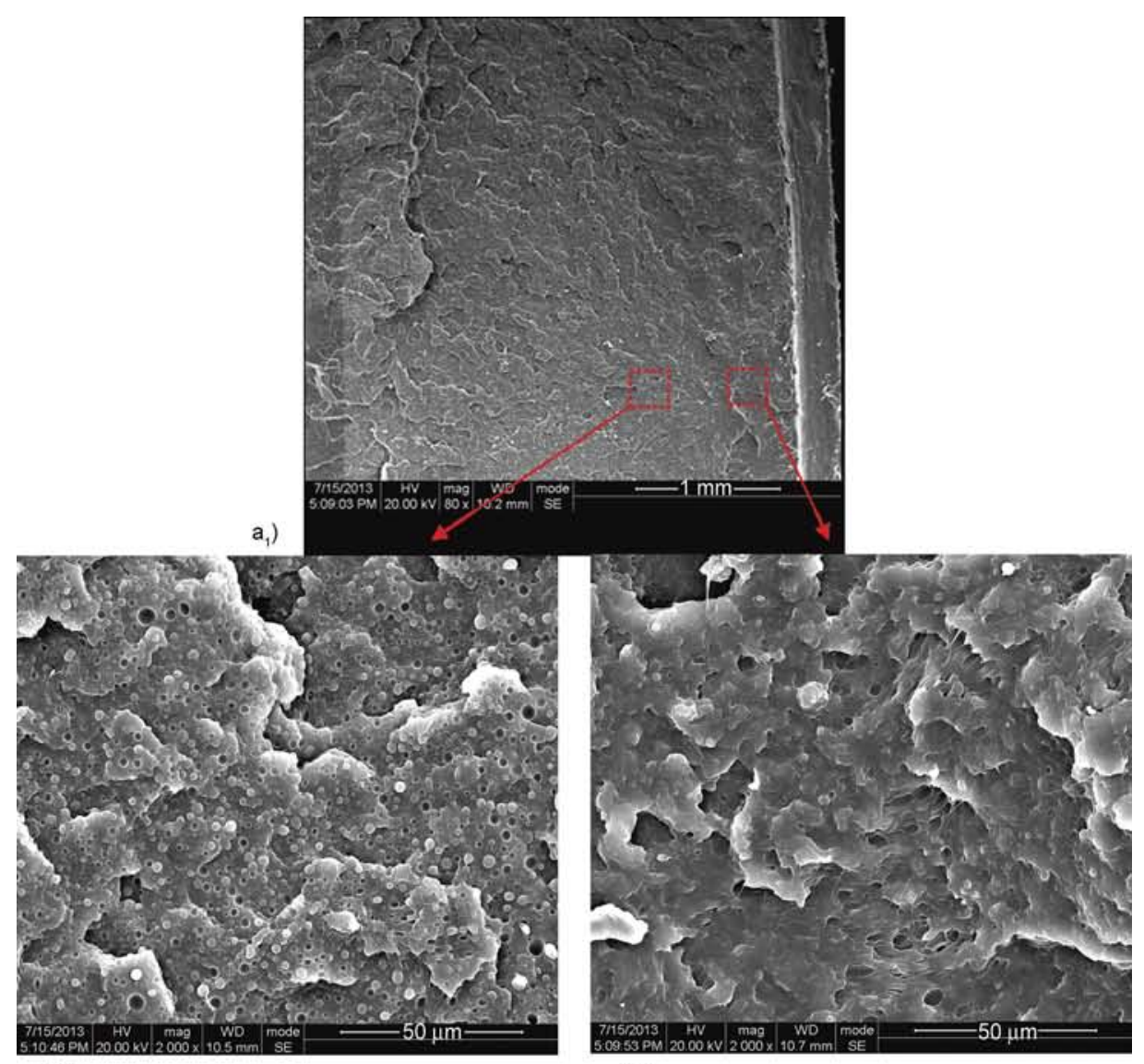

$a_{2}$ )

$\left.a_{3}\right)$

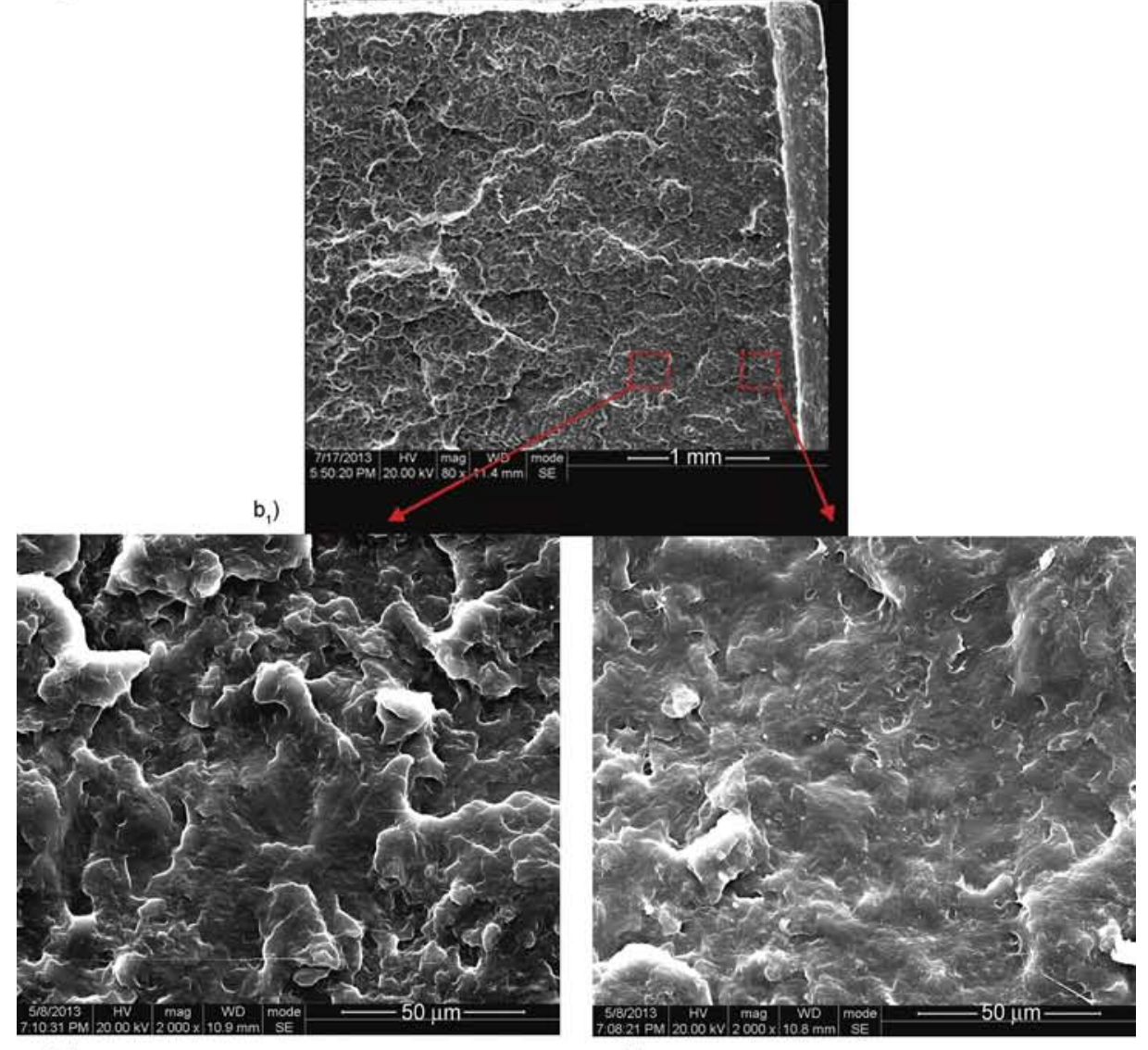

$b_{2}$ )

$b_{3}$ )

Figure 7. Typical impact-fractured surfaces morphologies of $\left(a_{1}\right) 2 P O E 20 / 2 P P$ and $\left(b_{1}\right) 2 \mathrm{NA} 0.05 / 2 P P$ iNA; ( $\left.a_{2}\right)$, $\left(a_{3}\right)$ enlarged view of sub-region marked in $\left(a_{1}\right) ;\left(b_{2}\right),\left(b_{3}\right)$ enlarged view of sub-region marked in $\left(b_{1}\right)$ 
achieved by the heterogeneous distribution of toughening agents while the tensile strength kept constant. Although the method to prepare the composites looks like somewhat cumbersome, it really proves that uniformly distribution is not always the best way to achieve the high performance of polymeric composites. That may give researchers some hints to creatively manipulate the composite structures.

\section{Acknowledgements}

This work was supported by the National Natural Science Foundation of China (51121001 and 51210005) and the Special Funds for Major State Basic Research Projects of China (2011CB606006).

\section{References}

[1] Zhang N., Li M., Nie J., Sun F.: Microstructure and surface property of macroscopic gradient polymer initiated by polysiloxane benzophenone photoinitiators with different silicone chain lengths. Journal of Materials Chemistry, 22, 9166-9172 (2012).

DOI: 10.1039/C2JM30270E

[2] Koide S., Yazawa K., Asakawa N., Inoue Y.: Fabrication of functionally graded bulk materials of organic polymer blends by uniaxial thermal gradient. Journal of Materials Chemistry, 17, 582-590 (2007).

DOI: $10.1039 / \mathrm{B} 614001 \mathrm{G}$

[3] Ahankari S., Kar K. K.: Mechanical properties of functionally graded carbon black-styrene butadiene rubber composites: Effect of modifying gradation and average filler loading. Journal of Applied Polymer Science, 125, 3469-3476 (2012).

DOI: $10.1002 / a p p .36704$

[4] Misra N., Kapusetti G., Pattanayak D. K., Kumar A.: Fabrication and characterization of epoxy/silica functionally graded composite material. Indian Journal of Physics, 85, 1393-1404 (2011).

DOI: $10.1007 / \mathrm{s} 12648-011-0161-0$

[5] Bafekrpour E., Simon G. P., Habsuda J., Naebe M., Yang C., Fox B.: Fabrication and characterization of functionally graded synthetic graphite/phenolic nanocomposites. Materials Science and Engineering: A, 545, 123-131 (2012).

DOI: $10.1016 /$ j.msea.2012.02.097

[6] Lee N-J., Jang J.: The effect of fibre-content gradient on the mechanical properties of glass-fibre-mat/polypropylene composites. Composites Science and Technology, 60, 209-217 (2000).

DOI: 10.1016/S0266-3538(99)00122-0
[7] Wang Y-Q., Wang Y., Zhang H-F., Zhang L-Q.: A novel approach to prepare a gradient polymer with a wide damping temperature range by in-situ chemical modification of rubber during vulcanization. Macromolecular Rapid Communications, 27, 1162-1167 (2006).

DOI: $10.1002 /$ marc. 200600106

[8] Geng C., Su J., Han S., Wang K., Fu Q.: Hierarchical structure and unique impact behavior of polypropylene/ethylene-octene copolymer blends as obtained via dynamic packing injection molding. Polymer, 54, 3392-3401 (2013).

DOI: $10.1016 /$ j.polymer.2013.04.048

[9] Yang J., Zhang Y., Zhang Y.: Brittle-ductile transition of PP/POE blends in both impact and high speed tensile tests. Polymer, 44, 5047-5052 (2003). DOI: $10.1016 / \mathrm{S} 0032-3861(03) 00438-5$

[10] Chen X., Yu J., Luo Z., Guo S., He M., Zhou Z.: Study on mechanical properties and phase morphology of polypropylene/polyolefin elastomer/magnesium hydroxide ternary composites. Polymers for Advanced Technologies, 22, 657-663 (2011).

DOI: $10.1002 /$ pat. 1561

[11] Bai S-L., Wang G-T., Hiver J-M., G'Sell C.: Microstructures and mechanical properties of polypropylene/polyamide 6/polyethelene-octene elastomer blends. Polymer, 45, 3063-3071 (2004).

DOI: $10.1016 /$ j.polymer.2004.02.070

[12] Li K., Huang H-X.: Detecting impact toughness of polypropylene/poly(ethylene-co-octene) blends with various morphologies induced via chaotic and shear mixing. Polymer Engineering and Science, 52, $2157-$ 2166 (2012).

DOI: $10.1002 /$ pen.23177

[13] Xu L., Zhong G-J., Ji X., Li Z-M.: Crystallization behavior and morphology of one-step reaction compatibilized microfibrillar reinforced isotactic polypropylene/poly(ethylene terephthalate) $(i \mathrm{PP} / \mathrm{PET})$ blends. Chinese Journal of Polymer Science, 29, 540-551 (2011).

DOI: $10.1007 / \mathrm{s} 10118-011-1066-2$

[14] Benavente R., Caveda S., Pérez E., Blazquez E., Peña B., van Grieken R., Suárez I.: Influence of $\beta$-nucleation on polymorphism and properties in random copolymers and terpolymers of propylene. Polymer Engineering and Science, 52, 2285-2295 (2013). DOI: $10.1002 /$ pen. 23322

[15] Luo F., Wang J., Bai H., Wang K., Deng H., Zhang Q., Chen F., Fu Q., Na B.: Synergistic toughening of polypropylene random copolymer at low temperature: $\beta$ modification and annealing. Materials Science and Engineering: A, 528, 7052-7059 (2011).

DOI: $10.1016 /$ j.msea.2011.05.030 
[16] Obadal M., Čermák R., Baran N., Stoklasa K., Šimoník J.: Impact strength of $\beta$-nucleated polypropylene. International Polymer Processing, 19, 35-39 (2004).

DOI: $10.3139 / 217.1802$

[17] Kotek J., Raab M., Baldrian J., Grellmann W.: The effect of specific $\beta$-nucleation on morphology and mechanical behavior of isotactic polypropylene. Journal of Applied Polymer Science, 85, 1174-1184 (2002). DOI: 10.1002/app.10701

[18] Han L., Wang Y., Liu L., Xiang F-M., Huang T., Zhou Z-W.: Crystallization, mechanical and thermal properties of sorbitol derivatives nucleated polypropylene/ calcium carbonate composites. Chinese Journal of Polymer Science, 28, 457-466 (2010).

DOI: $10.1007 / \mathrm{s} 10118-010-9051-8$

[19] Grein C., Gahleitner M., Bernreitner K.: Mechanical and optical effects of elastomer interaction in polypropylene modification: Ethylene-propylene rubber, poly-(ethylene-co-octene) and styrene-butadiene elastomers. Express Polymer Letters, 6, 688-696 (2012). DOI: $10.3144 /$ expresspolymlett.2012.74

[20] Wahit M. U., Hassan A., Mohd Ishak Z. A., Czigány T.: Ethylene-octene copolymer (POE) toughened polyamide 6/polypropylene nanocomposites: Effect of POE maleation. Express Polymer Letters, 3, 309-319 (2009). DOI: 10.3144/expresspolymlett.2009.39

[21] Jiao Y-H., Wang X-L., Wang Y-Z., Chen L., Mu S-M., Li F.: Relationship between microstructure and mechanical properties of ethylene-octene copolymer reinforced and toughened PP. Journal of Macromolecular Science Part B: Physics, 48, 351-364 (2009).

DOI: $10.1080 / 00222340802680001$

[22] Výchopňová J., Habrová V., Obadal M., Čermák R., Čabla R.: Crystallization of polypropylenewith a minute amount of $\beta$-nucleator. Journal of Thermal Analysis and Calorimetry, 86, 687-691 (2006).

DOI: $10.1007 / \mathrm{s} 10973-006-7894-6$

[23] Chvátalová L., Navrátilová J., Čermák R., Raab M., Obadal M.: Joint effects of molecular structure and processing history on specific nucleation of isotactic polypropylene. Macromolecules, 42, 7413-7417 (2009). DOI: $10.1021 / \mathrm{ma} 9005878$

[24] Varga J., Menyhárd A.: Effect of solubility and nucleating duality of $N, N^{\prime}$-dicyclohexyl-2,6-naphthalenedicarboxamide on the supermolecular structure of isotactic polypropylene. Macromolecules, 40, 2422-2431 (2007).

DOI: $10.1021 / \mathrm{ma} 062815 \mathrm{j}$

[25] Zhao S., Cai Z., Xin Z.: A highly active novel $\beta$-nucleating agent for isotactic polypropylene. Polymer, 49, 2745-2754 (2008).

DOI: $10.1016 /$ j.polymer.2008.04.012
[26] Hanim H., Fuad M. Y. A., Zarina R., Mohd Ishak Z. A., Hassan A.: Properties and structure of polypropylene/ polyethylene-octene elastomer/nano $\mathrm{CaCO}_{3}$ composites. Journal of Thermoplastic Composite Materials, 21, 123-140 (2008). DOI: $10.1177 / 0892705707083634$

[27] Luo F., Wang K., Ning N., Geng C., Deng H., Chen F., Fu Q., Qian Y., Zheng D.: Dependence of mechanical properties on $\beta$-form content and crystalline morphology for $\beta$-nucleated isotactic polypropylene. Polymers for Advanced Technologies, 22, 2044-2054 (2011). DOI: $10.1002 /$ pat. 1718

[28] Luo F., Xu C. L., Wang K., Deng H., Chen F., Fu Q.: Exploring temperature dependence of the toughening behavior of $\beta$-nucleated impact polypropylene copolymer. Polymer, 53, 1783-1790 (2012). DOI: $10.1016 /$ j.polymer.2012.02.024

[29] Tai C. M., Li R. K. Y., Ng C. N.: Impact behaviour of polypropylene/polyethylene blends. Polymer Testing, 19, 143-154 (2000).

DOI: $10.1016 / \mathrm{S} 0142-9418(98) 00080-4$

[30] Keledi G., Sudár A., Burgstaller C., Renner K., Móczó J., Pukánszky B.: Tensile and impact properties of threecomponent PP/wood/elastomer composites. Express Polymer Letters, 6, 224-236 (2012).

DOI: 10.3144 /expresspolymlett.2012.25

[31] Zhao N., Rödel H., Herzberg C., Gao S-L., Krzywinski S.: Stitched glass/PP composite. Part I: Tensile and impact properties. Composites Part A: Applied Science and Manufacturing, 40, 635-643 (2009).

DOI: $10.1016 /$ j.compositesa.2009.02.019

[32] Thomason J. L.: The influence of fibre length, diameter and concentration on the impact performance of long glass-fibre reinforced polyamide 6,6. Composites Part A: Applied Science and Manufacturing, 40, 114124 (2009).

DOI: $10.1016 /$ j.compositesa.2008.10.013

[33] Li J. X., Cheung W. L.: Effect of mould temperature on the formation of $\alpha / \beta$ polypropylene blends in injection moulding. Journal of Materials Processing Technology, 63, 472-475 (1997). DOI: $10.1016 / \mathrm{S} 0924-0136(96) 02667-2$

[34] Varga J.: Supermolecular structure of isotactic polypropylene. Journal of Materials Science, 27, 25572579 (1992). DOI: $10.1007 / \mathrm{BF} 00540671$

[35] Yuan Q., Jiang W., An L.: Study of $\beta-\alpha$ recrystallization of the polypropylene. Colloid and Polymer Science, 282, 1236-1241 (2004). DOI: $10.1007 / \mathrm{s} 00396-004-1063-\mathrm{x}$ 